\title{
The effect of perforations on the uplift capacity of skirted foundations on clay
}

Xiaojun Li* (corresponding author)

PhD Student

Centre for Offshore Foundation Systems and ARC CoE for Geotechnical Science and Engineering

The University of Western Australia

835 Stirling Hwy

9 Crawley, Perth, WA 6009

10 Australia

11 Tel: +61(0) 864888160

12 Fax: +61 (0) 864881044

13 Email: 21006228@student.uwa.edu.au

49 Manuscript submitting for publication to the Canadian Geotechnical Journal on 19 March 3013

50 Number of words: 5058, excluding abstract and references

51 Number of tables: 4

52 Number of figures: 15

\section{Christophe Gaudin}

Professorial research Fellow

Centre for Offshore Foundation Systems and ARC CoE for Geotechnical Science and Engineering

The University of Western Australia

35 Stirling Hwy

Crawley, Perth, WA 6009

Australia

Tel: $+61(0) 864887289$

Fax: +61 (0) 864881044

Email: christophe.gaudin@uwa.edu.au

\section{Yinghui Tian}

Assistant Professor

Centre for Offshore Foundation Systems and ARC CoE for Geotechnical Science and Engineering

The University of Western Australia

35 Stirling Hwy

Crawley, Perth, WA 6009

Australia

Tel: +61 (0) 864887076

(0) 864881044

Mark J. Cassidy

Winthrop Professor

Centre for Offshore Foundation Systems, The UWA Oceans Institute and ARC CoE for Geotechnical Science and Engineering

The University of Western Australia

35 Stirling Hwy

Arawley, Perth, WA 6009

Fax: +61 (0) 864881044

Email: mark.cassidy@uwa.edu.au 
54 Abstract: The retrieval of deep water subsea installations resting on soft soil, such as

55 "mudmat" shallow foundations, can be a difficult and costly operation if significant

56 resistance to uplift is experienced. At the mudmat invert, suctions may develop,

57 increasing the uplift resistance to greater than the weight of the mat. In this paper, a series

58 of centrifuge model tests are performed to determine the uplift resistance of rectangular

59 mudmats resting on lightly over-consolidated kaolin clay. The study investigates the

60 influence of perforation, in combination with skirt length and eccentric uplift, on the

61 uplift resistance and suction generation at the foundation invert. The outcomes

62 demonstrate that the central and eccentric uplift of mudmats have different failure

63 mechanisms, resulting in a different distribution of excess pore pressure at the foundation

64 invert. In contrast, perforations do not change the failure mechanism and only alter the

65 magnitude of suction generated. The two different configurations of perforation

66 investigated significantly reduce the suction at the mat invert and the uplift resistance,

67 and may potentially shorten the operating time for centred uplift. The combination of

68 perforation and eccentric uplift has the most beneficial effect on the reduction of the

69 uplift resistance.

71 Key words: centrifuge modelling; mudmat; clay; perforation; uplift resistance; suction 


\section{INTRODUCTION}

74 Mudmats are a type of shallow raft foundation used to support various temporary and

75 semi-permanent subsea structures, such as Pipeline End Manifolds and Terminations

76 (PLEMs/PLETs). They are an easily installed and economical solution commonly used in

77 deep water oil and gas developments. In order to provide sufficient resistance to

78 withstand horizontal loads from the thermal expansion of pipelines and jumpers,

79 mudmats are usually designed with skirts, which are embedded into the seabed by a

80 fraction of the mudmat width. Upon completion of the project, and in some instances to

81 comply with environmental regulations, mudmats must be decommissioned and removed

82 from the seabed.

83 The standard removal procedure for mudmats is to attach cables to the load points on the

84 structures, these cables are then pulled by a lift vessel at sea level to extract the mudmat

85 from the seabed. The uplift forces required for removal from the seabed are resisted not

86 only by the self-weight of the submerged mudmat, but also by the suction forces

87 potentially developing at the mudmat invert. In soft soil with low permeability, such as

88 the clays or silts commonly encountered in deep waters, these suction forces can be equal

89 to twice the submerged weight of the mudmat (Bouwmeester et al., 2009). In extreme

90 cases, the suction forces may be greater than the lifting capacity of the vessel and lead to

91 hazards during removal (Reid, 2007).

92 Various mitigation measures to reduce the generation of negative pressures (or suction) at

93 mudmat inverts have been investigated, using both in-situ data and laboratory 
94 experiments. It was expected that perforations would limit the development of suction at

95 the mudmat invert by shortening the drainage path. Lieng and Bjorgen (1995) reported

96 that even a small perforation (with respect to the total mudmat area) can lead to a

97 significant reduction in peak uplift resistance. During field trials, a reduction of about

$9850 \%$ of the uplift resistance was observed for a perforation ratio of $3.1 \%$ (defined as the

99 plan area of perforating holes with respect to the total area). White et al. (2005)

100 demonstrated that a large number of small perforations were more efficient in reducing

101 the uplift ratio than a small number of large perforations. Their results can be used to

102 maximize the ratio of vertical compression to uplift resistance. An alternative mitigation

103 solution involves applying the uplift load with an eccentric movement to facilitate

104 breakaway at the mudmat invert and hence reduce the magnitude of the suction forces

105 generated. From small scale model tests, Reid (2007) reported a reduction up to 66\%

106 (compared to the centred uplift resistance) by applying the pull-out load at the edge of the

107 mudmat. Water jetting at the invert is also a proven method to reduce uplift forces for

108 offshore jack-up rigs embedded foundations, as demonstrated by Gaudin et al. (2011).

109 However, the logistics associated with the jetting method are significantly more complex

110 and costly than typical lifting devices.

111 Chen et al. (2012) presented a comprehensive investigation of the uplift resistance of

112 mudmats, combining the effects of eccentric uplift, loading rate and skirt length in a

113 model test programme performed in a geotechnical centrifuge. Chen et al. (2012)

114 demonstrated that the uplift resistance was directly correlated to the development of

115 suction at the mat invert and that fully undrained conditions (characterised by a full

116 reverse end bearing mechanism) were achieved at normalised uplift velocities three 
117 orders of magnitude higher than those usually considered for shallow foundations in

118 compression. This is because a suction relief mechanism develops at the foundation-soil

119 interface during uplift, but while the system is in compression, the pore pressure

120 dissipation mechanism is governed by pore pressures in the far field (Lehane et al., 2008).

121 In contrast, fully drained conditions that would lead to low uplift resistance require uplift

122 rates too slow to be practically undertaken in-situ and partially drained conditions may be

123 prevalent during uplift of prototype mudmats. Accordingly, the prediction of uplift

124 resistance is hindered by difficulties in assessing the relevant drainage conditions and the

125 associated bearing capacity factor. Additional results from Chen et al. (2012), associated

126 with eccentric uplift, indicated that a different failure mechanism was taking place,

127 favouring the suction relief mechanism and hence contributing to a significant reduction

128 in the uplift resistance.

129 This paper presents a series of model mudmat tests performed in a geotechnical drum 130 centrifuge. The research aims to advance Chen et al. (2012)'s study by linking 131 perforation and uplift eccentricity in order to (i) further understand the mechanism

132 governing suction development at the invert of a perforated mudmat, and (ii) provide

133 recommendations to optimise a retrieval strategy in order to minimise the uplift resistance

134 and the associated risk and cost. In particular, the generation of suction at the mat invert

135 and the uplift force vs. displacement curves were monitored during centrifuge model tests, 136 and were considered as a function of the effective width, the mudmat skirt length and the 137 uplift eccentricity. 


\section{DETERMINATION OF THE UPLIFT CAPACITY}

139 As detailed in Chen et al. (2012), the ultimate uplift resistance of mudmats is controlled

140 by the operative shear strength of the soil and the failure mechanism during uplift. The

141 failure mechanism can be assumed to be either a reverse end bearing type (Craig and

142 Chua, 1990; Acosta-Martinez et al., 2008; Gourvenec et al., 2009; Randolph et al., 2011;

143 Mana et al., 2012) or a breakout hemispherical type (Yu, 2000; Rattley, 2007) depending

144 on the level of suction mobilised at the mat invert. Following the compression convention,

145 the uplift capacity of mudmats in clay can be expressed as

$146[1]$

$$
q_{u}=N_{c} s_{\text {uop }}-\gamma^{\prime} h
$$

147 where $N_{c}$ is the bearing capacity factor, $S_{\text {uop }}$ the operative shear strength of the soil at

148 the skirt tips, $\gamma^{\prime}$ the submerged unit weight of the soil and $h$ the skirt length, which

149 accounts for the embedment of the foundation. The second term on the right hand side of

150 the equation is the correction for overburden. For skirted foundations, the overburden

151 stress is cancelled by the weight of soil column incorporated by the skirts (see Fig. 1).

152 Therefore, the uplift capacity of a skirted mudmat, regardless of the failure mechanism,

153 can be determined by

$154[2]$

$$
q_{u}=N_{c} s_{\text {uop }}
$$

155 Rigorous solutions to determine the bearing capacity factor of a strip footing on 156 homogeneous clay under vertical loading have been developed by Prandtl (1921) and

157 Reissner (1924) and yielded a value of $N_{c}=5.14$. In non-homogeneous soil, $N_{c}$ 158 increases with the soil heterogeneity $k B_{0} / s_{\text {um }}$, where $B_{0}$ is the width of the footing, $k$ the 159 gradient of the soil profile and $s_{u m}$ the initial soil undrained strength at the mudline (Davis 
160 and Booker, 1973; Randolph et al., 2004), as illustrated in Fig. 1. The full reverse end

161 bearing capacity can be assessed using solutions derived from the undrained compression

162 capacity (eq. [2]), since for fully undrained conditions, uplift and compression capacities

163 are theoretically equal.

164 The ultimate bearing capacity of two or more parallel strips has also received attention

165 from Martin and Hazell (2005), Gourvenec and Steinepreis (2007) and Bransby et al.

166 (2010), providing insights into the effect of perforations on the bearing capacity of

167 shallow foundations under undrained soil conditions.

168 The operative shear strength of the soil, $s_{\text {uop }}$, is taken as the shear strength at the skirt tip,

$169 S_{\text {uo }}$, which can be determined using the standard T-bar test (Stewart and Randolph, 1991;

170 1994), potentially enhanced by soil strain rate effects. Einav and Randolph (2005) and

171 Lehane et al. (2009), among others, reported that the soil strength increases with strain

172 rate by approximately 5\%-20\% per log cycle of increasing strain rate. This can be

173 expressed as

174 [3]

$$
S_{\text {uop }}=S_{u 0, \text { ref }}\left[1+\mu \log \left(\frac{\dot{\gamma}}{\dot{\gamma}_{\text {ref }}}\right)\right]
$$

175 where $s_{u 0 \text {,ref }}$ is the soil shear strength at a reference strain rate $\dot{\gamma}_{\text {ref }}$ (which can be taken as

$176 s_{u 0}$ from the T-bar test) of $0.0001 \mathrm{~s}^{-1}$, and $\mu$ is a rate parameter of approximately 0.1 for

177 normally consolidated kaolin clay (Randolph et al., 2005). Atkinson (2000) suggested

178 that the average operational strain rate underneath a rectangular shallow foundation

179 subjected to vertical loading can be approximated as $v / 3 B_{0}$ (where $v$ is uplift velocity and

$180 B_{0}$ is the width of the mat). Assuming that full contact is maintained between the 
181 foundation and the soil during uplift, a similar approach may be assumed for the present 182 scenario.

183 The uplift force during model tests can therefore be expressed as

$184[4]$

$$
F_{u p}=N_{c} s_{\text {uop }} A+G^{\prime}
$$

185 where $F_{u p}$ represents the peak uplift force and $G^{\prime}$ the submerged self-weight of the 186 mudmat. Note that in the present study, the gross area $A$ is used to calculate uplift force 187 regardless of the configuration of perforations.

\section{3. EXPERIMENTAL SET-UP}

\section{$189 \quad 3.1$ Facility}

190 The drum centrifuge at Centre for Offshore Foundation Systems (COFS), The University 191 of Western Australia (UWA) was used to carry out the described tests, as it enables 192 multiple mudmat uplift tests to be conducted in one single soil sample. The ring channel 193 of the centrifuge has an outer diameter of $1.2 \mathrm{~m}$, an inner diameter of $0.8 \mathrm{~m}$ and a channel 194 height (sample width) of $0.3 \mathrm{~m}$. A servo-controlled actuator was mounted on the central 195 tool table to provide both vertical and radial movements. The tool table can be coupled to 196 the channel or may rotate independently of it, allowing it to be stopped for examination 197 or changing the tool, without affecting the soil sample. A complete technical description 198 of this centrifuge is presented in Stewart et al. (1998). Tests were performed at a 199 centrifuge acceleration of 150 g, i.e. all model linear dimensions are scaled by 150 and all 200 loads by $150^{2}$ (see Garnier et al., 2007 for details on similitude principles). 
202 Three types of model mudmats were fabricated using aluminium plates, with dimensions 203 of $5 \mathrm{~mm}$ in thickness $(d), 100 \mathrm{~mm}$ in length $\left(L_{0}\right)$ and $50 \mathrm{~mm}$ in width $\left(B_{0}\right)$. This 204 represents a prototype mudmat $15 \mathrm{~m}$ long and $7.5 \mathrm{~m}$ wide. The overall dimensions are 205 identical to models tested by Chen et al. (2012).

206 One non-perforated model (labelled B) and two types of perforated models (labelled P1 207 and P2) were considered (see Fig. 2). Model P1 featured large perforations with 36 208 circular holes $6.0 \mathrm{~mm}$ in diameter (Fig. 2b). The second model, P2, featured small 209 perforations, comprising 171 circular holes $2.7 \mathrm{~mm}$ in diameter (Fig. 2c). Both perforated 210 models had the same perforation ratio, $\alpha$, of 0.19 , defined as the ratio of the area of the

211 holes to the gross area. Each perforated model was made with removable skirts with a 212 length $(h)$ of $0 \mathrm{~mm}, 5 \mathrm{~mm}$ and $10 \mathrm{~mm}(0 \mathrm{~m}, 0.75 \mathrm{~m}$ and $1.5 \mathrm{~m}$ in embedment prototype, 213 respectively), while the non-perforated mudmat models were fabricated with the same 214 skirt lengths for benchmarking. Both model and prototype dimensions are summarised in 215 Table 1.

216 The models were equipped with three Pore Pressure Transducers (PPTs), as illustrated in 217 Fig. 2 and 3, to monitor variations in pore pressure at the foundation invert. As the PPTs' 218 housing was too large to be fitted between perforations, they were installed in place of a 219 single perforation as illustrated in Fig. 2b and 2c. In order to examine the effect of central 220 and eccentric uplifts, three small holes (illustrated in Fig. 2a) were drilled to allow a 221 vertical ball shaft to be screwed onto the model plate and connected to a loading cell by a 222 tong, (illustrated in Fig. 3). Uplift was applied via the ball shaft and the uplift resistance 223 was measured by a $500 \mathrm{~N}$ capacity load cell. 
224 The effective width $(W)$ of each model was defined to represent the average length of

225 drainage paths between perforations (White et al., 2005). For mudmats with circular

226 perforations, the effective strip width $W$ was calculated as (see Figure 4):

$$
W=\frac{x+\sqrt{2}\left(x+d_{0}\right)-d_{0}}{2}
$$

228 where $d_{0}$ is the diameter of circular perforations and $x$ represents the shortest drainage

229 path between the perforations, as illustrated in Fig. 4. From eq. [5], it was calculated that

$230 W$ is $6.07 \mathrm{~mm}$ (0.91 $\mathrm{m}$ in prototype) for mudmat $\mathrm{P} 1$ and $3.34 \mathrm{~mm}$ (0.5 $\mathrm{m}$ in prototype) for

231 mudmat P2. For the non-perforated mudmat B, $W$ is simply taken as the average of length

232 and width, e.g. $\left(B_{0}+L_{0}\right) / 2=75 \mathrm{~mm}(11.25 \mathrm{~m}$ in prototype).

\subsection{Soil sample preparation and characterisation}

234 Two soil samples were prepared for the present study. Kaolin slurry, prepared at a water 235 content of $\sim 120 \%$ (approximately twice the liquid limit), was poured into the centrifuge 236 channel under an acceleration of $20 \mathrm{~g}$, over a preplaced $10 \mathrm{~mm}$ thick drainage blanket at

237 the bottom. Self-weight consolidation under two-way drainage was achieved by spinning 238 the centrifuge at $150 \mathrm{~g}$ for approximately four days. The degree of consolidation was 239 monitored by measuring pore pressure dissipation via PPTs located at the bottom of the 240 channel and settlement of the top surface of the soil. After full consolidation was 241 achieved, a soil layer 5 to $15 \mathrm{~mm}$ thick was scraped off the surface to create a lightly 242 over-consolidated soil sample with a flat surface, enabling a good contact between the 243 model and the soil. The final height of both samples was $150 \mathrm{~mm}$ (including the drainage 244 layer). 
245 T-bar tests were performed in both soil samples to evaluate the undrained shear strength.

246 Tests were carried out by using a $5 \mathrm{~mm}$ diameter, $20 \mathrm{~mm}$ long T-bar at a standard

247 penetration rate of $1 \mathrm{~mm} / \mathrm{s}$, ensuring undrained soil conditions (Stewart and Randolph

248 1991; 1994). As a first approximation, a constant bearing factor $N_{\text {T-bar }}=10.5$ derived

249 from plastic solution (Randolph and Houlsby, 1984) and experimental calibration (Low et

250 al., 2010) were adopted to convert the measured T-bar resistance into undrained shear

251 strength. Following the procedure proposed by White et al. (2010), lower bearing factors

252 were applied to characterise the T-bar penetration resistance at shallow depths, where full

253 flow of soil around the T-bar cylinder cannot occur. A cyclic test was also included in

254 each penetration test to obtain accurate calibration data for soil penetration resistance

255 (Randolph et al., 2007).

256 Fig. 5 summarises the corrected undrained shear strength profiles at prototype scale in 257 both soil samples. In general, soil strength profiles in both soil samples exhibited an 258 excellent repeatability, with sample two featuring a more linear increase in strength with 259 depth. The corrected soil strength for both samples can be idealised as bilinear profiles.

260 At shallow depths ( $z<0.75-0.6 \mathrm{~m}$ for samples one and two, respectively), the soil

261 samples were over consolidated following the trimming process and exhibiteded a

262 constant shear strength with depth, with values of $s_{u} \sim 3.26 \mathrm{kPa}$ and $s_{u} \sim 1.68 \mathrm{kPa}$ for

263 samples one and two, respectively. Soil strength at higher depths can be idealised by

264 linear profiles with gradients of $k \sim 1.01 \mathrm{kPa} / \mathrm{m}$ for sample one and $\sim 1.06 \mathrm{kPa} / \mathrm{m}$ for

265 sample two, resulting in a heterogeneity ratio of $k B_{0} / s_{u m} \sim 2.3$ and $\sim 4.7$, respectively. 
267 Nine central uplift tests were performed in soil sample one and nine eccentric uplift tests

268 were performed in sample two, both under a centrifuge acceleration level of $150 \mathrm{~g}$, as

269 summarised in Table 2. Model mudmats were installed on the soil surface at $1 \mathrm{~g}$ and

270 consolidation under the weight of the foundation was achieved at $150 \mathrm{~g}$. A constant uplift

271 velocity of $v=3 \mathrm{~mm} / \mathrm{s}$ was applied to the model once all excess pore pressures at the mat

272 invert were fully dissipated, indicating that full consolidation under self-weight had been

273 achieved. A constant water table of $50 \mathrm{~mm}$ above the soil surface was maintained during

274 each test.

\section{4. TEST RESULTS}

\subsection{Typical measurements of uplift force and pore pressure}

277 Typical central uplift load/displacement and excess pore pressure/displacement curves

278 are presented for tests S1-1 and S1-4 in Fig. 6. The general patterns were consistent with

279 Chen et al. (2012)'s observations that uplift resistance experienced a sudden increase to

280 reach a peak value $\left(F_{u p}\right)$ over a short distance $\left(w_{p}\right)$, then reduced to a semi-residual value

281 which was slightly higher than the submerged self-weight $\left(G^{\prime}\right)$ of the model mudmats due

282 to the soil attached at the model invert. $G^{\prime}$ differed between tests due to the different skirt

283 lengths and configurations of perforation (see Table 1). G' also changed slightly with

284 uplift displacement due to the changing acceleration level along the radius in the

285 centrifuge (see dashed line in Fig. 6), and this has been accounted for in the analysis.

286 The excess pore pressure displacement curves exhibit the same pattern as the load 287 displacement curves, indicating a close correlation between pore pressure generation at 
288 the foundation invert and the uplift resistance. The negative values indicate the 289 generation of suction at the mudmat invert, with peak values represented by $p_{1}, p_{2}$ and $p_{3}$

290 being coincident with the peak uplift resistance, indicating that uplift resistance is

291 sustained by the development of suction at the mudmat invert. It is noteworthy that the

292 uplift force for perforated mudmats, e.g. S1-4 and the associated suction at the mat invert

293 is less sustainable compared to that for non-perforated mudmats, e.g. S1-1. This is

294 attributed to shortening of the drainage path resulting from perforation and the associated

295 acceleration in the dissipation of pore pressures. More details on the effects of

296 perforations will be provided in the next section.

297 The peak values of the uplift forces $\left(F_{\text {up }}\right)$, the peak value of the excess pore pressures 298 monitored by the three PPTs $\left(p_{1}, p_{2}\right.$ and $\left.p_{3}\right)$ and their average values $\bar{p}(=$ $\left.299\left(p_{1}+p_{2}+p_{3}\right) / 3\right)$, and the distance travelled to reach the peak uplift force $\left(w_{p}\right)$ for all the 300 eighteen uplift tests are summarised in Table 2 for further interpretation.

301 The distances required to reach peak uplift forces, $w_{p}$, are presented in Fig. 7 as a 302 function of the skirt length. The operational distance decreased with decreasing skirt 303 length, regardless of the configuration of perforations, and both perforated mudmats 304 exhibited a significantly lower operational distance during uplift compared to the non305 perforated mudmat. Fig. 8 provides some insight into the secant stiffness $\left(E_{s}\right)$ of the soil 306 under vertical uplift, calculated as the normalised peak extraction resistance $F_{\text {up }} / \mathrm{A}$ 307 divided by the normalised skirt displacement, $w_{p} / B$. Mudmats with perforations generated 308 a stiffer response than non-perforated mudmats, while the stiffness for all mats was 309 reduced with increased skirt length (Fig. 8). This occured because mudmats with 310 perforation and shallower skirts generate a much shallower failure mechanism. As shown 
311 in Fig. 7, peak uplift force occurred faster for the perforated mudmats for the same skirt

312 length (while uplifted at the same velocity), suggesting that the perforated design could

313 be a promising method for saving uplift expenses by reducing operating time in the field.

\section{$314 \quad 4.2$ Effect of perforation combined with skirt length}

315 Fig. 9 presents the net peak uplift forces, $F_{u p, n e t}\left(=F_{u p}-G^{\prime}\right)$, normalised by the gross area

316 (i.e. $\left.F_{u p, n e t} / A\right)$ and the corresponding peak values of average pore pressures $(\bar{p})$ varying

317 with the effective width for central uplift tests. It is evident that the peak uplift force

318 decreases with reducing effective width and shallower skirt embedment. The peak uplift

319 forces for tests on the perforated mudmat (P1) were reduced by almost half compared to

320 the non-perforated mudmat (B), indicating that the perforation had beneficial effects in

321 reducing the uplift resistance of mudmats. For a same perforation ratio of 0.19 , the

322 reduction in effective width resulted in a further reduction of uplift resistance of about

$32330 \%$. For a specific configuration of perforation, the reduction in skirt length resulted in a

324 reduction of the uplift force by up to $50 \%$ for the largest effective width. This

325 improvement significantly reduced, however, with reduced effective width. As

326 anticipated, this reduction of peak uplift force was associated with a concomitant

327 reduction in average peak suction, due to the shortening of the drainage paths by either

328 perforations or decreased skirt embedment, which accelerated the dissipation of the

329 negative pore pressure generated by the uplift mechanism.

330 The net peak uplift forces (normalised by gross area $A$ ) are also plotted against the

331 associated average suctions in Fig. 10. Fig. 10 demonstrates that the uplift resistance was

332 essentially sustained by the suction at the foundation invert, independent of the skirt 
333 length and the perforation. Consequently, the mudmat failure mode was a reverse end

334 bearing failure mechanism (see illustration in Fig. 10), as observed and described by

335 Craig and Chua (1990), Acosta-Martinez et al. (2008), Gourvenec et al. (2009), Randolph

336 et al. (2011) and Mana et al. (2012) rather than a breakout contraction type mechanism

337 (Yu 2000; Rattley 2007). This demonstrates that fully undrained conditions are

338 experienced by the soil during uplift. Drainage conditions may be assessed by calculating

339 the dimensionless velocity $v B_{0} / c_{v}$ (Finnie and Randolph 1994; Chung et al. 2006), where

$340 c_{v}$ is the coefficient of consolidation of the soil, typically equal to $1.5 \mathrm{~m}^{2} /$ year for kaolin

341 clay at a stress level of about10 kPa (House et al. 2001).

342 In the present study, the dimensionless velocity for the non-perforated mudmat was about

343 3000, where undrained soil conditions for uplift can be assumed according to Chen et al.

344 (2012). The dimensionless velocity for perforated mudmats was approximately one order

345 less than for non-perforated mudmats if normalised by the effective width $W$, i.e. $v W / c_{v}$

$346 \sim 400$ and $\sim 200$ for P1 and P2, respectively. This potentially lead to partially drained

347 conditions within the soil that would explain the lower uplift capacity. This is however

348 inconsistent with observations from Fig. 10, and will be discussed further in the

349 following paragraphs.

350 In order to provide further insights into the drainage conditions and failure mechanisms 351 associated with skirt length and the configuration of perforations, the bearing capacity

352 factors for central uplift tests have been calculated from eq. [4] and are summarised in

353 Table 3. Fig. 11 presents the bearing capacity factors for non-perforated mudmats (B) as

354 a function of skirt length in comparison with limit analysis results from Randolph et al. 
355 (2004) and experimental results from Chen et al. (2012). Results from Randolph et al.

356 (2004) are presented for a soil heterogeneity of $k B_{0} / s_{u m}=0,3$ and 10 , encompassing the

357 heterogeneity of the soil samples. The bearing capacity factors for non-perforated mats

358 ranged from 6.84 to 8.37 with skirt length ratio $\left(h / B_{0}\right)$ varying from 0 to 0.2 . This agrees

359 well with those obtained by Chen et al. (2012) in soil samples of a similar heterogeneity

360 ratio (ranging from 3.38 to 3.61 ) indicating good repeatability of the present tests. They

361 also compare reasonably well with the limit analysis solutions of Randolph et al. (2004),

362 although there is a trend for an overestimation of the bearing capacity factor for flat

363 foundations (i.e. $\left.h / B_{0}=0\right)$.

364 Fig. 12 presents the bearing capacity factors for all the three model mudmats as a

365 function of the effective width. There is an evident trend of reduction of bearing factors

366 with reduced effective width. It is also noteworthy that the effect of the embedment,

367 which increases bearing capacity factors (see Randolph et al., 2004), reduced as the

368 effective width decreased. As mentioned previously, the reduction in bearing capacity

369 factors could be attributed to an accelerated dissipation of excess pore pressures with

370 increased occurrence of perforations. However, the load/displacement curves in Fig. 6,

371 and pull-out stiffness in Fig. 8, indicate that perforated mats exhibited a stiffer load

372 displacement response, and a faster generation of suction at the foundation invert. Both

373 observations demonstrate that the drainage conditions for perforated mats were also

374 undrained, and that the reduction in uplift capacity (and associated bearing capacity

375 factors) was essentially due to an earlier onset of suction breakaway at the mat invert 376 caused by the perforations. 
377 No theoretical solutions have been established to determine bearing capacity factors for

378 perforated mudmats. The closest solution is the one developed by Martin and Hazell

379 (2005), who established bearing capacity factors using the method of characteristics for

380 2D surface multi-strip footings subjected to downward vertical loadings under undrained

381 conditions. Results from Martin and Hazell (2005) are plotted in Fig. 13 for soil

382 heterogeneity ratios ranging from 0 to 5 . They indicated a trend of reducing bearing

383 capacity factor with increasing perforation ratio, beyond a value that depends on the

384 strength heterogeneity ratio.

385 The perforation ratio used by Martin and Hazell (2005) in Fig. 13 is defined under 2D

386 plane strain condition as the ratio of total footing spacing to the total width, so a

387 distinction cannot be made between the perforation ratio and the effective width, as for

388 the 3D models. In order to enable a direct comparison with the experimental results, an

389 equivalent perforation ratio $\alpha^{*}$ was calculated for mudmats P1 and P2, as illustrated in the

390 inset in Fig. 13. The equivalent perforation ratio $\alpha^{*}$ was calculated by converting the

391 shaded area $A_{s h}$ into an equivalent width $y$, resulting in values of $0,0.28$ and 0.23 for

392 mudmat B, P1 and P2, respectively. Bearing capacity factors for the three mudmats are

393 plotted in Fig.13, considering the equivalent perforation ratio, for comparison with results

394 from Martin and Hazell (2005).

395 Bearing capacity factors for the non-perforated mat agreed reasonably well with results

396 from Martin and Hazell (2005), accounting for the effects of heterogeneity ratio and skirt

397 length. The agreement was also satisfactory for the perforated mat P1, but not for the

398 perforated mat P2, as Martin and Hazell (2005) only modelled two-dimensional strips

399 that cannot account for the effect of different perforated patterns. Nevertheless, the results 
400 suggest that Martin and Hazell (2005) might be used as a first approximation to evaluate

401 the effect of perforation on uplift capacity, provided that the effective width is not

402 reduced by more than a factor of 10 , compared to a plain foundation of identical overall

403 dimensions.

$404 \quad 4.3$ Effect of eccentric loading combined with perforation

405 Fig. 14 presents typical variation of uplift force and pore pressures with uplift 406 displacement for the eccentric uplift test S2-7. The mudmat experienced a rotational soil 407 failure mechanism (as illustrated in Fig. 14) about a point located close the centre of the 408 mudmat. This resulted in positive excess pressures being mobilised at the end farthest 409 from the lifting side (instrumented with PPT1) and negative excess pore pressures at the 410 lifting side (instrumented with PPT3). The peak excess pore pressures at the mat for all 411 the eccentric uplift tests (refer to Table 2) is presented in Fig. 15.

412 Fig. 15 presents the approximate pore pressure profile along the length of the mudmats $413\left(L_{0}\right)$ at failure. Note that PPT3 in test S2-6 ceased to function during the test, so no data is 414 available (Fig. 15c). It can be seen that the perforation did not change the general failure 415 mechanism as detailed above, which remained rotational. The perforation lead to lower 416 suction being generated at the uplift side, but is unlikely to have significantly affected the 417 excess pore pressure on the opposite side, indicating that they are most likely generated 418 by the increase in bearing pressure resulting from the self-weight of the foundation being 419 applied on a smaller section of the mat as it is being uplifted. It is also noteworthy that 420 the centre of rotation of the mudmat moves away from the lifting point with increasing 421 skirt length. As the skirt length increases, a deeper failure mechanism is generated, with 422 breakaway at the mudmat invert occurring later during uplift. 
424 Table 4 summarises the ratio of measured uplift resistance to central uplift resistance for

425 all tests. The reported values enable comparison between eccentric and centered uplift

426 tests, and configurations of perforations. For the non-perforated mudmat, the eccentric

427 uplift considered reduced the peak resistance by $66 \%$ to $79 \%$ compared to central uplift

428 tests, decreasing with increasing skirt length due to the deeper failure mechanisms

429 mobilised with longer skirts. When a large number of small perforations were introduced

430 (mudmat P2), the peak uplift resistance was reduced by about $74 \%$ compared to the

431 central uplift of non-perforated mudmats, with less effect from the skirt length. In

432 contrast, a small number of large perforations (mudmat P1) yielded a reduction in uplift

433 capacity of only $45 \%$ indicating that the effective width is the relevant parameter when

434 determining the effect of perforation. In summary, the results indicate that eccentric uplift

435 appears to be more efficient in reducing the uplift resistance than perforation ratio (for the

436 range considered in this study), although both reduce the uplift capacity by generating an

437 early breakaway at the foundation invert. Eccentric uplift is indeed more efficient in

438 reducing the uplift capacity, as the breakaway can propagate more rapidly along a larger

439 surface. However the efficiency of eccentric uplift is hindered by higher skirt embedment,

440 whereas the central uplift capacity of perforated mudmat is less affected by skirt lengths.

441 By combining eccentric uplift and perforations, the mudmats experience the highest

442 reduction in uplift resistance, with a reduction of $\sim 76 \%$ for mudmat P1 and $\sim 93 \%$ for

443 mudmat P2 (i.e. the uplift force is only slightly larger than the self-weight of the mat),

444 with skirt length having only a relatively small effect. 
446 A series of centrifuge tests were undertaken to assess the effect of perforations and

447 loading eccentricity on the uplift capacity of subsea mudmats. The results demonstrated

448 that the uplift capacity in all cases is essentially sustained by the generation of suction

449 pressures at the mudmat invert, and that undrained soil conditions prevailed for all tests,

450 regardless of the configuration of perforation. The reduction of uplift capacity, which can

451 reach up to $\sim 80 \%$, results from the breakaway of suction at the foundation invert, which

452 can be generated either by perforations or by eccentric uplift. Eccentric uplift was

453 observed to have a much greater effect in reducing the uplift capacity than perforations,

454 although the benefit reduces with increasing skirt embedment.

\section{ACKNOWLEDGEMENTS}

456 The work described here forms part of the activities of the Centre for Offshore 457 Foundation Systems (COFS), the ARC Centre of Excellence for Geotechnical Science 458 and Engineering (ARC CE110001009) and the Lloyd's Register Foundation Chair and 459 Centre of Excellence in Offshore Foundations.

\section{LIST OF SYMBOLS}

461 B non-perforated mudmat

$462 \quad$ P1 big perforated mudmat

463 P2 small perforated mudmat

$464 \quad$ A $\quad$ gross area 


\begin{tabular}{|c|c|c|}
\hline 465 & $A_{s h}$ & shaded area \\
\hline 466 & $B_{0}$ & width \\
\hline 467 & $d$ & thickness \\
\hline 468 & $d_{0}$ & diameter \\
\hline 469 & $c_{V}$ & coefficient of consolidation \\
\hline 470 & $e$ & eccentricity \\
\hline 471 & $E_{s}$ & secant stiffness \\
\hline 472 & $F_{\text {up }}$ & peak uplift force \\
\hline 473 & $F_{\text {up,net }}$ & net peak uplift force \\
\hline 474 & $G^{\prime}$ & submerged self-weight \\
\hline 475 & $h$ & skirt length or embedment \\
\hline 476 & $k$ & gradient of soil strength \\
\hline 477 & $L_{0}$ & length \\
\hline 478 & $N_{c}$ & bearing capacity factor \\
\hline 479 & $N_{\text {T-bar }}$ & bearing capacity factor for T-bar \\
\hline 480 & $p_{1}, p_{2,} p_{3}$ & peak suction monitored by PPT1, PРT2 and PPT3 \\
\hline 481 & $\bar{p}$ & average suction $\left(=\left(p_{1}+p_{2}+p_{3}\right) / 3\right)$ \\
\hline 482 & $q_{u}$ & uplift resistance \\
\hline 483 & $s_{u}$ & soil undrained shear strength \\
\hline 484 & $S_{\text {um }}$ & initial soil strength at mudline \\
\hline 485 & $s_{u o}$ & soil strength at skirt tip \\
\hline 486 & $S_{u o, r e f}$ & reference soil strength \\
\hline 487 & $S_{\text {uop }}$ & operative soil strength at skirt tip \\
\hline
\end{tabular}




$\begin{array}{lll}488 & v & \text { velocity } \\ 489 & x & \text { shortest drainage path } \\ 490 & y & \text { equivalent width } \\ 491 & Z & \text { depth } \\ 492 & W & \text { effective width } \\ 493 & w_{p} & \text { peak uplift distance } \\ 494 & \alpha & \text { perforation ratio } \\ 495 & \alpha^{*} & \text { equivalent perforation width } \\ 496 & \gamma^{\prime} & \text { submerged unit weight of soil } \\ 497 & \dot{\gamma}^{2} & \text { strain rate } \\ 498 & \dot{\gamma}_{r e f} & \text { reference strain rate } \\ 499 & \mu & \text { strain rate parameter }\end{array}$

\section{REFERENCES}

501 Acosta-Martinez, H.E., Gourvenec, S.M. and Randolph, M.F. 2008. An experimental 502 investigation of a shallow skirted foundation under compression and tension. Soil and 503 Foundation, 48(2): 247-254.

504 Atkinson, J.H. 2000. Non-linear stiffness in routine design. Géotechnique, 50(5): 487-508.

505 Bouwmeester, D., Peuchen, J., Van der Wal, T., Sarata, B., Willemse, C.A., Van Baars, 506 S., Peelen, R. 2009. Prediction of breakout force for deep water seafloor objects. 507 Proceedings of the offshore Technology Conference, Houston, OTC 19925. 
508 Bransby, M.F., Hudacsek, P., Knappett, J.A. and Brown, M.J., Morgan, N., Cathie, D.N., 509 Egborge, R., Maconochie, A., Yun, G.J., Brown, N., Ripley, A. 2010. The vertical 510 bearing capacity of grillage foundations in sand. ISFOG II, Perth, pp. 409-414.

511 Chen, R., Gaudin, C. and Cassidy, M.J. 2012. Investigation of the vertical uplift capacity 512 of deep water mudmats in clay. Canadian Geotechnical Journal, 49(7): 853-865. doi: $513 \quad 10.1139 / \mathrm{t} 2012-037$.

514 Chung, S.F., Randolph, M.F. and Schneider, J.A. 2006. Effect of penetration rate on 515 penetration resistance in clay. J. Geotech. Geoenviron. Engng, ASCE, 132(9): 1188516 1196. doi: 10.1061/(ASCE)1090-0241(2006)132:9(1188).

517 Craig, W.H. and Chua, K. 1990. Extraction forces for offshore foundations under 518 undrained loading. J. Geotech. Engng. Div., ASCE, 116(5): 868-884.

519 Davis, E.H. and Booker, J.R. 1973. The effect of increasing strength with depth on the 520 bearing capacity of clays. Géotechnique, 23(4): 551-563.

521 Einav, I. and Randolph, M.F. 2005. Combining upper bound and strain path methods for 522 evaluating penetration resistance. International Journal for Numerical Methods in 523 Engineering, 63(14): 1991-2016. doi: 10.1002/nme.1350.

524 Finnie, I.M.S. and Randolph, M.F. 1994. Punch-through and liquefaction induced failure 525 of shallow foundations in calcareous sediments. Proc. Int. Conf. on Behaviour of 526 Onshore Structures, BOSS'94, Boston, pp. 217-230.

527 Garnier, J., Gaudin, C., Springman, S., Culligan, P.J., Goodings, D., Konig, D., Kutter, B., 528 Phillips, R., Randolph, M.F. and Thorel, L. 2007. Catalogue of scaling laws and 
529 similitude questions in geotechnical centrifuge modelling. International Journal of $530 \quad$ Physical Modelling in Geotechnics, 7(3): 1-23.

531 Gaudin C., Bienen B. and Cassidy M.J. (2011). Investigation of the potential of bottom 532 water jetting to ease spudcan extraction in soft clay. Géotechnique. 61(12): 1043-1054..

533 Gourvenec, S. and Steinepreis, M. 2007. Undrained limit states of shallow foundations 534 acting in consort. International Journal of Geomechanics, 7(3): 194-205. doi: $535 \quad$ 10.1061/(ASCE)1532-3641(2007)7:3(194).

536 Gourvenec, S., Acosta-Martinez, H.E. and Randolph, M.F. 2009. Experimental study of 537 uplift resistance of shallow skirted foundations in clay under transient and sustained 538 concentric loading. Géotechnique, 59(6): 525-537. doi: 10.1680/geot.2007.00108.

539 House, A.R., Oliveira, J.R.M.S. and Randolph, M.F. 2001. Evaluating the coefficient of 540 consolidation using penetration tests. International Journal of Physical Modelling in 541 Geotechnics, 1(3): 17-26. doi: 10.1680/ijpmg.2001.1.3.17.

542 Lehane, B.M., Gaudin, C., Richards, D.J. and Rattley, M.J. 2008. Rate effects on the 543 vertical uplift capacity of footings founded in clay. Géotechnique, 58(1):13-22. doi: $544 \quad$ 10.1680/geot.2008.58.1.13.

545 Lehane, B., O'Loughlin, C.D., Gaudin, C. and Randolph, M.F. 2009. Rate effects on 546 penetrometer resistance in kaolin. Géotechnique, 59(1): 41-52. doi: $547 \quad$ 10.1680/geot.2007.00072.

548 Lieng, J.T. and Bjorgen, H.P. 1995. New flow-through mudmat design for Heidrun 549 subsea structure. Proceedings of the offshore Technology Conference, Houston, OTC $550 \quad 7671$. 
551 Low, H.E., Lunne, T., Andersen, K.H., Sjursen, M.A., Li, X. and Randolph, M.F. 2010.

552 Estimation of intact and remoulded undrained shear strength from penetration tests in 553 soft clays. Géotechnique, 60(11): 843-859. doi: 10.1680/geot.9.P.017.

554 Mana, D.S.K., Gourvenec, S., Randolph, M.F. and Hossain, M.S. 2012. Failure 555 mechanisms of skirted foundations uplift and compression. International Journal of 556 Physical Modelling in Geotechnics, 12(2): 47-62. doi: 10.1680/ijpmg.11.00007.

557 Martin, C.M. and Hazell, E.C.J. 2005. Bearing capacity of parallel strip footings on non558 homogeneous clay. Proc. Int. Symp. on Frontiers in Offshore Geotechnics, Perth, pp. $559 \quad 427-433$.

560 Prandtl, L. 1921. Eindringungsfestigkeit und festigkeit von schneiden. Zeit angew $561 \quad$ Mathematic and Mechanic, 1(1):15-20.

562 Randolph, M.F. and Houlsby, G.T. 1984. The limiting pressure on a circular pile loaded 563 laterally in cohesive soil. Géotechnique, 34(4): 613-623.

564 Randolph, M.F., Jamiolkowski, M.B. and Zdravković, L. 2004. Load carrying capacity of 565 foundations. Proceedings of the Skempton Memorial Conference. London, England, 566 Vol. 1, pp. 207-240.

567 Randolph, M.F., Cassidy, M.J., Gourvenec, S. and Erbrich, C.T. 2005. The challenges of 568 offshore geotechnical engineering. Proceedings of the 16th International Conference on 569 Soil Mechanics and Geotechnical Engineering, Osaka, Japan, Vol. 1, pp.123-176.

570 Randolph, M.F., Low, H.E. and Zhou, H. 2007. In situ testing for design of pipeline and 571 anchoring systems. Proceedings of the 6th International Offshore Site Investigation and 
572 Geotechnics Conference: Confronting New Challenge and Sharing Knowledge, 573 London, UK, pp. 251-262.

574 Randolph M.F., Gaudin C., Gourvenec, S.M., White D.J., Boylan, N., Cassidy M.J. 2011.

575 Recent advances in offshore geotechnics for deep water oil and gas developments.

576 Ocean Engineering. 38(7): 818-834. doi: 10.1016/j.oceaneng.2010.10.021

577 Rattley, M. J. 2007. The Uplift behavior of shallow foundations. PhD thesis, University 578 of Southampton, UK.

579 Reid, M. 2007. Re-deployable subsea foundations. Diploma thesis, University of $580 \quad$ Cambridge.

581 Reissner, H. 1924. Zum erddruck problem. Proc. 1st International Congress on Applied 582 Mechanics, pp. 295-311.

583 Stewart, D.P. and Randolph, M.F. 1991. A new site investigation tool for the centrifuge.

584 Proc. Int. Conf. on Centrifuge Modelling-Centrifuge 91, Boulder, Colorado, pp. 531$585 \quad 538$.

586 Stewart, D.P. and Randolph, M.F. 1994. T-bar penetration testing in soft clay. J. Geotech. 587 Engng. Div., ASCE, 120(12): 2230-2235.

588 Stewart, D.P., Boyle, R.S. and Randolph, M.F. 1998. Experience with a new drum 589 centrifuge. Pro. Int. Conf. Centrifuge, Tokyo, Japan, Vol. 1, pp. 35-40.

590 White, D.J., Maconochie, A.J., Cheuk, C.Y., Joray, D., Bolton, M.D. and Springman, 591 S.M. 2005. An investigation into the bearing capacity of perforated mudmats. Frontiers 592 in Offshore Geotechnics, ISFOG, Perth, pp. 459-465. 
593 White, D.J., Gaudin, C. and Zhou, H. 2010. Interpretation of T-bar penetrometer tests at

594 shallow embedment and in very soft soils. Canadian Geotechnical Journal, 47(2): 218595 229. doi: 10.1139/T09-096.

596 Yu, H. S. 2000. Cavity expansion methods in geomechanics. Kluwer Academic. 


\section{List of Tables}

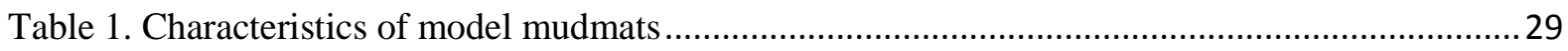

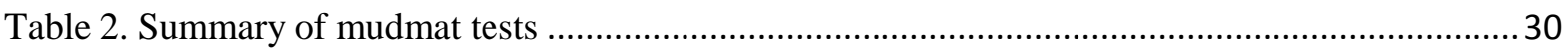

Table 3. Bearing capacity factors inferred from central uplift tests....................................................31

Table 4. Ratio of uplift resistance to central uplift resistance for all mudmat tests ..............................32 
Table 1. Characteristics of model mudmats.

\begin{tabular}{|c|c|c|c|c|c|c|c|c|c|}
\hline \multirow{2}{*}{$\begin{array}{l}\text { Mudmat } \\
\text { type* }\end{array}$} & \multirow{2}{*}{$\begin{array}{l}\text { Perforated ratio } \alpha \\
(-)\end{array}$} & \multicolumn{2}{|l|}{ Skirt length $h$} & \multicolumn{2}{|c|}{ Perforated diameter $d_{0}$} & \multicolumn{2}{|c|}{ Effective width $W$} & \multicolumn{2}{|c|}{ Submerged weight $G^{\prime}$} \\
\hline & & Model (mm) & Prototype (m) & Model (mm) & Prototype (m) & Model (mm) & Prototype (m) & Model (N) & Prototype (MN) \\
\hline \multirow[t]{3}{*}{ B } & - & 0 & 0.00 & - & - & 75.00 & 11.25 & 62 & 1.40 \\
\hline & - & 5 & 0.75 & - & - & 75.00 & 11.25 & 66 & 1.49 \\
\hline & - & 10 & 1.50 & - & - & 75.00 & 11.25 & 70 & 1.58 \\
\hline \multirow[t]{3}{*}{ P1 } & 0.19 & 0 & 0.00 & 6.0 & 0.90 & 6.07 & 0.91 & 52 & 1.17 \\
\hline & 0.19 & 5 & 0.75 & 6.0 & 0.90 & 6.07 & 0.91 & 56 & 1.26 \\
\hline & 0.19 & 10 & 1.50 & 6.0 & 0.90 & 6.07 & 0.91 & 60 & 1.35 \\
\hline \multirow[t]{3}{*}{$\mathrm{P} 2$} & 0.19 & 0 & 0.00 & 2.7 & 0.41 & 3.34 & 0.50 & 56 & 1.26 \\
\hline & 0.19 & 5 & 0.75 & 2.7 & 0.41 & 3.34 & 0.50 & 60 & 1.35 \\
\hline & 0.19 & 10 & 1.50 & 2.7 & 0.41 & 3.34 & 0.50 & 64 & 1.44 \\
\hline
\end{tabular}

* $\mathrm{B}=$ mudmat without perforations; $\mathrm{P} 1=$ =mudmat with large perforations; $\mathrm{P} 2=$ =mudmat with small perforations 
Table 2. Summary of mudmat tests.

\begin{tabular}{|c|c|c|c|c|c|c|c|c|c|}
\hline $\begin{array}{l}\text { Soil sample } \\
\text { \& test no. }\end{array}$ & $\begin{array}{l}\text { Mudmat } \\
\text { type }\end{array}$ & $\begin{array}{l}\text { Skirt length } \\
h(\mathrm{~mm})\end{array}$ & $\begin{array}{l}\text { Eccentricity } \\
e(\mathrm{~mm})\end{array}$ & $\begin{array}{l}\text { Peak uplift } \\
\text { force } F_{u p}(\mathrm{~N})\end{array}$ & $\begin{array}{l}\text { Peak suction } \\
p_{1}(\mathrm{kPa})\end{array}$ & $\begin{array}{l}\text { Peak suction } \\
p_{2}(\mathrm{kPa})\end{array}$ & $\begin{array}{l}\text { Peak suction } \\
p_{3}(\mathrm{kPa})\end{array}$ & $\begin{array}{l}\text { Average suction } \\
\bar{p}(\mathrm{kPa})\end{array}$ & $\begin{array}{l}\text { Peak uplift } \\
\text { distance } w_{p}(\mathrm{~mm})\end{array}$ \\
\hline S1-1 & $\mathrm{B}$ & 0 & 0 & 199.1 & -21.8 & -28.5 & -25.6 & -25.3 & 1.07 \\
\hline S1-2 & & 5 & 0 & 224.0 & -33.5 & -39.2 & -41.5 & -38.1 & 1.51 \\
\hline S1-3 & & 10 & 0 & 276.6 & -44.2 & -44.5 & -44.7 & -44.5 & 1.99 \\
\hline S1-4 & $\mathrm{P} 1$ & 0 & 0 & 127.8 & -16.7 & -20.3 & -19.6 & -18.9 & 0.42 \\
\hline S1-5 & & 5 & 0 & 140.5 & -11.3 & -24.0 & -23.8 & -19.7 & 0.63 \\
\hline S1-6 & & 10 & 0 & 174.7 & - & - & -28.3 & -28.3 & 0.83 \\
\hline S1-7 & $\mathrm{P} 2$ & 0 & 0 & 88.3 & -4.5 & - & -11.4 & -8.0 & 0.26 \\
\hline S1-8 & & 5 & 0 & 102.2 & -6.8 & -12.8 & -16.5 & -12.0 & 0.31 \\
\hline S1-9 & & 10 & 0 & 109.8 & -11.2 & -12.3 & -12.7 & -12.1 & 0.43 \\
\hline S2-1 & B & 0 & 40 & 75.1 & 9.5 & -2.1 & -22.1 & -14.7 & 1.82 \\
\hline S2-2 & & 5 & 40 & 98.3 & 12.7 & -5.1 & -43.0 & -11.8 & 2.90 \\
\hline S2-3 & & 10 & 40 & 130.2 & 14.7 & -18.8 & -34.8 & -13.0 & 2.80 \\
\hline S2-4 & $\mathrm{P} 1$ & 0 & 40 & 68.5 & 5.9 & -2.1 & -19.1 & -5.1 & 0.42 \\
\hline S2-5 & & 5 & 40 & 75.0 & 8.9 & -1.0 & -27.3 & -6.5 & 2.04 \\
\hline S2-6 & & 10 & 40 & 92.4 & 21.8 & -8.7 & - & 6.6 & 2.54 \\
\hline S2-7 & P2 & 0 & 40 & 60.5 & 1.8 & 0.1 & -10.1 & -2.7 & 0.86 \\
\hline S2-8 & & 5 & 40 & 64.9 & 7.4 & 1.2 & -13.5 & -1.6 & 1.25 \\
\hline S2-9 & & 10 & 40 & 82.4 & 18.3 & -11.6 & -13.3 & -2.2 & 2.22 \\
\hline
\end{tabular}


Table 3. Bearing capacity factors inferred from central uplift tests.

\begin{tabular}{ll|lll}
\hline$h$ & $h / B_{0}$ & \multicolumn{3}{|c}{$N_{c}$} \\
\hline $\mathrm{mm}$ & - & $\mathrm{B}$ & $\mathrm{P} 1$ & $\mathrm{P} 2$ \\
\hline 0 & 0 & 6.84 & 3.76 & 1.74 \\
5 & 0.1 & 7.88 & 4.26 & 2.10 \\
10 & 0.2 & 8.37 & 4.70 & 2.14 \\
\hline
\end{tabular}


Table 4. Ratio of uplift resistance to central uplift resistance for all mudmat tests.

\begin{tabular}{lllllll}
\hline Mudmat type & $\mathrm{B}$ & $\mathrm{B}$ & $\mathrm{P} 1$ & $\mathrm{P} 1$ & $\mathrm{P} 2$ & $\mathrm{P} 2$ \\
Eccentricity & $e / L_{0}=0$ & $e / L_{0}=0.4$ & $e / L_{0}=0$ & $e / L_{0}=0.4$ & $e / L_{0}=0$ & $e / L_{0}=0.4$ \\
\hline$h / B_{0}=0$ & 1.00 & 0.21 & 0.55 & 0.23 & 0.25 & 0.06 \\
$h / B_{0}=0.1$ & 1.00 & 0.36 & 0.54 & 0.24 & 0.27 & 0.05 \\
$h / B_{0}=0.2$ & 1.00 & 0.44 & 0.56 & 0.24 & 0.26 & 0.09 \\
\hline
\end{tabular}




\section{List of Figures}

Fig. 1. Symbols and notations

Fig. 2. Model mudmats (a) without perforations (B), (b) with large perforations (P1) and (c) with

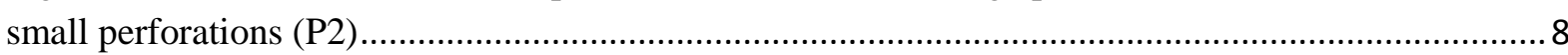

Fig. 3. Model mudmat instrumented with PPTs and a ball shaft during testing .................................. 9

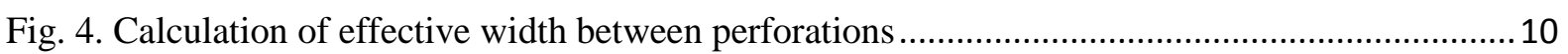

Fig. 5. Undrained shear strength profile for (a) sample one and (b) sample two.................................11

Fig. 6. Typical measurement of uplift resistances and excess pore pressures vs. displacement (S1-1: no perforation, no skirt; S1-4: small perforations, no skirt).............................................................. 12

Fig. 7. Peak uplift distance varying with skirt length for central uplift tests (Mudmat type: $B=$ no perforation; P1=big perforations; P2=small perforations) …............................................................ 13

Fig. 8. Secant stiffness varying with skirt length for central uplift tests (Mudmat type: $B=$ no perforation; P1=big perforations; $\mathrm{P} 2=$ =small perforations)

Fig. 9. Net uplift resistance and average suction varying with effective width for central uplift tests (Mudmat type: B=no perforation; P1=big perforations; $\mathrm{P} 2=$ =small perforations)

Fig. 10. Net uplift resistance varying with average suction pressures (Mudmat type: $\mathrm{B}=$ no perforation;

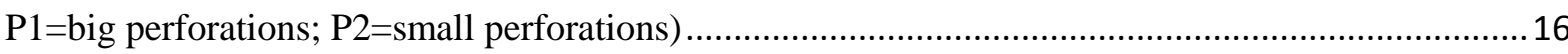

Fig. 11. Comparison of bearing capacity factors for varying skirt length ........................................17

Fig. 12. Bearing capacity factors varying with effective width (Mudmat type: B=no perforation; P1=big perforations; $\mathrm{P} 2=$ small perforations).

Fig. 13. Bearing capacity factors varying with perforation ratio (Mudmat type: $B=$ no perforation; $\mathrm{P} 1=$ big perforations; $\mathrm{P} 2=$ small perforations).....

Fig. 14. Measurement of uplift forces and excess pore pressures vs. displacement (S2-7: small perforations; no skirt; eccentricity $=40 \mathrm{~mm}$ ).

Fig. 15. Pore pressure profiles at mudmat inverts for eccentric uplifts (Mudmat type: $\mathrm{B}=$ no perforation; P1=big perforations; $\mathrm{P} 2=$ small perforations).... 